\title{
Opting out and opting in: understanding the complexities of women's career transitions
}

\author{
Elizabeth F. Cabrera \\ School of Global Management and Leadership, Arizona State University, \\ Phoenix, Arizona, USA
}

\begin{abstract}
Purpose - This study aims to explore the reasons why women are leaving the workplace. Are they opting out of the workforce to stay at home with their children as current media reports suggest, or are the reasons more complex as the Kaleidoscope Career Model (KCM) suggests? A second objective is to examine whether or not women's primary career motives change over time as predicted by the KCM. Lastly, the potential barriers or boundaries faced by women pursuing boundaryless careers will be identified.

Design/methodology/approach - A survey was sent to 2,000 randomly selected women graduates of an international business school located in the USA. The response rate was 25 percent, or 497 women.

Findings - The results revealed that 47 percent of the women surveyed had stopped working at some point in their career. Numerous reasons were cited for leaving. Only 35 percent of the women who stopped working cited rearing children as their sole reason for opting out. Sixty-two percent of the women reported that their career focus had changed. In line with the KCM predictions, mid-career women were most interested in finding balance in their lives and the desire for authenticity increased across the lifespan. Finally, 70 percent of the women who left eventually returned to work, debunking the myth that women opt out and do not return to the workforce. Our findings show that there are barriers that make it difficult to move across organizations, especially if time is taken off between jobs.

Research limitations/implications - All of the respondents in this study have a graduate degree in international business; thus, the results may have limited generalizability to other populations. Nonetheless, this study provides valuable data that helps us to better understand the complexities of women's career paths.

Originality/value - This study makes contributions to two different areas of career theory. First, it provides one of the first empirical tests of the $\mathrm{KCM}$. In addition to showing that women are leaving companies for more complex reasons than for family reasons alone, it also shows that women's primary career motives shift over time in the manner predicted by the KCM. Second, the study contributes to the literature on boundaryless careers by showing that there are in fact barriers or boundaries faced by women attempting to pursue careers across organizations.
\end{abstract}

Keywords Women workers, Careers

Paper type Research paper

\section{Introduction}

Women's participation in the workforce has grown steadily over the years, from 43 percent in 1970 to 59 percent in 2004 (US Bureau of Labor Statistics, 2005a). This increase has been especially noticeable in the professional and managerial fields, where women now occupy almost half of these positions. Yet despite this growing participation, women's careers are decidedly different from those of men. In particular, 
men tend to follow more linear career paths, whereas women's careers are more likely to be nonlinear, disjointed, and interrupted (Mainiero and Sullivan, 2006).

The nature of women's careers has received quite a bit of media attention lately, with the popular press claiming that many professional women are opting out of the workforce. Lisa Belkin first drew attention to the issue with her article on the "opt-out revolution" published in the New York Times Magazine (Belkin, 2003). In March of 2004 Time magazine published an article entitled "The case for staying home" (Wallis, 2004). More recently, the New York Times ran a story about Ivy League women who are setting a path to motherhood (Story, 2005). These women are planning on getting a law degree, an MBA, or a medical degree, and then expect to put their careers aside in order to rear their children.

This paper seeks to further our understanding of women's career transitions. We explore the reasons why women opt out of their careers and the extent to which they later opt back in. We also investigate the predictions of the Kaleidoscope Career Model (KCM) that women's primary career motives change across their life span. Lastly, we investigate the potential boundaries that women face in pursuing boundaryless careers.

\section{Factors influencing the decision to leave}

The media tends to portray women as leaving the workforce for family reasons. And it is true that there are a number of pull factors that clearly influence women's decisions to stop working. Caring for children or elderly parents or moving because of a spouse's job relocation are pull factors that may be especially strong for women. Women are relational; they value connectedness with others, often sacrificing their needs for others (Gilligan, 1982). Their career decisions are strongly influenced by how these decisions will affect significant others in their lives (Powell and Mainiero, 1992). Therefore, women often do choose to leave jobs or organizations for family reasons.

Many women choose to stop working completely in order to care for their children. Statistics show that this is an increasing trend; the number of children with stay-at-home mothers increased 13 percent in the past decade (Vanderkam, 2005). Other women do not quit altogether, but try to find an arrangement that lets them spend more time with their families. Schwartz (1989) introduced the term "mommy track" to refer to an alternative career path that allows a mother flexible or reduced work hours, but at the same time tends to slow or block advancement. A newly coined phrase, the "daughter track", refers to a late-in-life version of the mommy track where women are leaving their jobs to care for their aging parents (Gross, 2005). As with rearing children, women bear a disproportionate burden for elder care. Seventy-one percent of the people who devote 40 hours or more a week to care for aging relatives are women.

Women also opt out of the workforce to follow their spouses when their job requires that they relocate. A study of mobile spouses in dual-career marriages found that 82 percent of the accompanying spouses were women (Eby, 2001). The study also found that women were more likely than men to repeatedly move for their spouse.

In addition to these pull factors there are a number of push factors that, while mentioned less often in the media, may also be an important part of the career equation. Some of the more common push factors include a perceived lack of opportunity for advancement, discrimination, harassment, or disdain for the corporate culture 
(Mainiero and Sullivan, 2005). Much research has documented the challenges women face in their careers and the slow rate of change (Burke and Mattis, 2005; Burke and Vinnicombe, 2005, 2006; Vinnicombe and Bank, 2003; see also the special issue of CDI on women's careers that was edited by Burke and Vinnicombe). The number of women in top management positions remains very low (Burke and Vinnicombe, 2006) and the glass ceiling still exists, although in most cases it is now positioned at a higher level in the organizational hierarchy (Altman et al., 2005). In 2005 women represented only 16.4 percent of corporate officers among Fortune 500 companies, yet they made up 46.4 percent of the workforce (Catalyst, 2005). One reason for this is that more objective credentials are used for entry-level hires, which makes it easier to detect and prevent discrimination. However, decisions about top management positions tend to be less structured and systematic and are often based on subjective criteria which can lead to more biased decisions (Burke and Vinnicombe, 2006; Powell, 1999). The use of such criteria can lead to male candidates being favored over female candidates (Cross and Linehan, 2006), because, although gender stereotyping for managers does appear to be declining, there is still a preference for managers with masculine characteristics (Powell et al., 2002; Vinnicombe and Singh, 2002).

Fewer women in top positions means that lower-level female managers are often excluded from key networks and have fewer role models, both of which are so important for advancement. Women in Cross and Linehan's (2006) study reported the lack of access to informal male networks to be a significant barrier for women in reaching senior management positions. Another study found that social capital was more important to women's advancement to upper levels of management than was human capital (Terjesen, 2005). Role models are important because they inspire women to persevere by demonstrating that attaining certain levels of success is possible. Unfortunately, there are so few women at the top of organizations that female role models are hard to find (Singh et al., 2006). The limited opportunities for advancement, the lack of women role models in top positions, and the fact that women earn only 81 percent as much as their male colleagues (US Bureau of Labor Statistics, 2005b) may lead women to decide that the effort they are putting into their careers just is not worth it.

Another factor that has been widely recognized as pushing women out of corporate America is the masculinity of these organizational cultures. Traditional organizational cultures are masculine, characterized by competitiveness, zero-sum views of power, and hierarchical relations, where managerial decisions are based on masculine values of rationality, orderliness and conformity to authority (Maier, 1999).

These values are contrary to feminine values, which include positive feedback, peer cohesion, empowerment, and participation. Many women are uncomfortable working in organizations because they feel pressure to adopt behaviors that run counter to their values (van Vianen and Fischer, 2002). In Marshall's (1995) in-depth interviews of 16 women, 11 of them mentioned dissatisfaction and pressures related to working in male-dominated cultures and said the experiences were central in their decisions to leave their jobs. The women were disillusioned by behaviors they described as aggressive, territorial, political, and status-conscious. These behaviors are diametrically opposed to the relational values that most women hold which favor openness, consensus, collaboration and equality. 
Women may also feel uncomfortable in corporate cultures because of a clash between their ethical standards and those used in the business world. Decisions in business are often outcome-focused or utilitarian. This "justice view" of morality emphasizes universal standards, moral rules, and impartiality. Men tend to operate from a utilitarian or justice framework. Women, on the other hand, have traditionally been taught a "care view" of morality that emphasizes solidarity, community, and caring about one's special relationships (Gilligan, 1982). This "different voice" may cause women to experience conflict at work when they do not agree with decisions that are made by the typically male majority.

One final and obvious push factor is sexual harassment, which continues to be a problem for women in the workplace. In 2005, women filed 10,904 sexual harassment complaints with the EEOC (Equal Employment Opportunity Commission, 2006). This represents 86 percent of all sexual harassment complaints registered that year.

So, while the media tends to make the case that women leave the workforce for family reasons, it is likely not so simple. Mainiero and Sullivan (2006) suggest that a better name for the "opt-out revolution" would be the "opt-out revolt". They believe that women are leaving companies for complex reasons. Some may include revolting against of the push factors previously mentioned, while the fact that most organizations do not provide the flexibility they need to successfully combine work and family may be yet another reason for leaving. Furthermore, the authors suggest that women leave the workforce because their jobs are not meaningful or satisfying. They introduced the concept of Kaleidoscope Careers in order to offer a more comprehensive understanding of why women are leaving corporations (Mainiero and Sullivan, 2005).

The Kaleidoscope Career Model (KCM) describes how both men's and women's career patterns shift over time as their needs and interests change (Mainiero and Sullivan, 2006). According to the model there are three parameters that influence career decisions:

(1) authenticity;

(2) balance; and

(3) challenge.

Authenticity means being true to oneself. It leads people to look for work that is compatible with their values. Balance refers to the desire to successfully integrate one's work and non-work lives. Individuals today are less work-centric, choosing instead the "life track", based on the idea that it is better to work to live than to live to work. Lastly, challenge is the need that all individuals have to experience career advancement that contributes to feelings of self-worth. The authors explain that these three career motives are like the glass chips in a kaleidoscope. While they are always present, evolving life situations cause one of the parameters to be the primary focus at different points in time. Just as the glass chips of a kaleidoscope move to make new patterns, so do career patterns evolve in response to changing life priorities.

Based on the results of a number of studies, Mainiero and Sullivan (2006) discovered that men and women tend to follow different career patterns. They identified the Beta Kaleidoscope Career Pattern as more typical of women. It is characterized by a focus on challenge in early career, with balance becoming more important in mid career, and authenticity becoming the primary focus in late career. Men, on the other hand, more 
often follow the Alpha Kaleidoscope Career Pattern in which the focus moves from challenge in early career to authenticity in mid career to balance in late career.

The first objective of the current study is to explore the reasons why women stop working. We will test to see if, as the KCM suggests, the situation is more complex than the popular press media hype would have us believe. That is, we will examine whether or not women stop working primarily for family reasons or whether there are a number of other reasons that also lead women to leave corporations. A second aim of our study is to investigate the KCM claim that women's primary career motives shift over time, specifically from challenge to balance to authenticity.

\section{Boundaries to the boundaryless career}

Many women choose to opt out of the workforce, yet most of them eventually return to work. In their study of professional women, Hewlett and Luce (2005) found that 74 percent of the women who had left work voluntarily had returned. This, coupled with the fact that only 5 percent of the women surveyed were interested in rejoining the companies they left, implies that many women are pursuing boundaryless careers or careers that cross traditional organizational boundaries (Arthur and Rousseau, 1996). The boundaryless career is one of a number of more recently proposed career models that challenge the traditional definition of a career as a series of hierarchical moves within a single organization. The "protean career" (Hall, 1996), the "intelligent career" (Arthur et al., 1995), and the "post-corporate career" (Peiperl and Baruch, 1997) depict careers as being under the control of the individual, dynamic, horizontal rather than vertical, even multidirectional (Baruch, 2004).

It has been proposed that women might be especially well prepared for boundaryless careers (Fondas, 1996). Feminine traits may be more useful in a boundaryless context that requires cooperation, openness, and the nurturing of relationships. Women's experiences of moving away from corporate careers in order to balance work and non-work demands or avoid the glass ceiling may also help them to more easily manage boundaryless careers. Nevertheless, it has been pointed out that while careers today do have fewer boundaries than before, boundaries still exist (King et al., 2005; Sullivan, 1999) and there may in fact be negative consequences associated with the boundaryless career (Eby, 2001). DeFillippi and Arthur (1994), for example, identified the three competencies ("knowing-how", "knowing-whom", and "knowing-why") necessary for successful boundaryless or intelligent careers, suggesting that those lacking these competencies may be unsuccessful in their attempts to pursue a boundaryless career.

There is evidence that women do experience negative consequences when pursuing boundaryless careers. Eby (2001), in her study of the boundaryless career experiences of spouses, 87 percent of whom were women, who moved in order to accompany their partners in job-related relocations, found that the spouses reported losses in terms of salary and benefits as well as advancement opportunities in comparing their new job to their previous job. Valcour and Tolbert (2003) also discovered that women who followed boundaryless career patterns had significantly lower earnings. Actually, career interruptions have a negative impact on future income for both men and women. A recent study found that MBAs with early career interruptions earned 45 percent less than did those with no interruptions and that this difference existed even 25 years after the interruption (Reitman and Schneer, 2005). 
It may be that women's typically non-linear career experiences impact the knowing-how, knowing-whom, and knowing-why competencies that are critical for successful boundaryless careers. Knowing-how may be negatively affected because they lose opportunities to gain new job skills and their previously acquired skills may atrophy during the time they spend out of the workforce. Furthermore, women who take time off may be faced with fewer development opportunities when they return (Terjesen, 2005). Career interruptions may also be detrimental to knowing-whom. Access to key networks and mentoring relationships will be diminished for women who are no longer in the workforce.

On a positive note, it is possible that knowing-why may be enhanced when women voluntarily leave work, allowing them the opportunity to reassess what it is they really want from a career. Women may take advantage of the time spent away from work to explore what is truly important to them or to pursue a new career that more closely matches their values or the motives that are primary at that point in their lives. Or it may be that women quit their jobs precisely because they have a clear sense of what they want and their current job is not fulfilling their needs.

So a final objective of the current study is to explore the potential barriers or boundaries that women who pursue boundaryless careers face. If knowing-how and knowing-whom are negatively affected by taking time off, this will likely act as a barrier when these women try to return to the workforce.

\section{Methodology}

The participants in this study were women graduates of a top-ranked international business school located in the USA. Two thousand women graduates were randomly chosen from the school's alumni database. An online survey was sent to all women chosen who had a listed e-mail address (69 percent) and a survey was sent via mail to the remaining women. A total of 497 completed surveys were returned for a response rate of 25 percent. A total of 28 percent of the online surveys were returned and 18 percent of the mailed surveys were returned. Given that the preferred response rate for this type of study would be above 40 percent (Baruch, 1999), response bias was assessed by comparing background information of respondents to the individuals originally sent surveys. Chi-square analyses by graduation year and country indicated no evidence of response bias.

Respondents' ages ranged from 26 to 85 years old with a mean age of 41 . Thirty percent were under 36 years old, 46 percent were between 36 and 45 years old, 20 percent were between 46 and 55 years old, and only 4 percent were older than 55 . Most of the respondents (73 percent) earned their graduate degree between 1980 and 1999. Eleven percent graduated before 1980 and 16 percent of the respondents graduated after 1999. As far as salary is concerned, 38 percent of the respondents earned over $\$ 100,000$ a year, 37 percent earned between $\$ 60,000$ and $\$ 100,000$, and 25 percent earned less than $\$ 60,000$. While surveys were sent to graduates from 60 different countries, 82 percent of the individuals who returned the survey resided in North America, 7 percent in Asia, 8 percent in Europe or the Middle East, and 3 percent were from South America. Characteristics of the sample are shown in Table I.

In addition to the demographic information summarized above, the survey included a number of questions regarding the women's career experiences: 


\begin{tabular}{|c|c|c|c|}
\hline & M & $\mathrm{SD}$ & Percentage \\
\hline Age & 40.7 & 8.15 & \\
\hline \multicolumn{4}{|l|}{ Year graduated } \\
\hline Before 1970 & & & 1.3 \\
\hline 1970 to 1979 & & & 9.2 \\
\hline 1980 to 1989 & & & 31.9 \\
\hline 1990 to 1999 & & & 41.2 \\
\hline 2000 to 2004 & & & 16.3 \\
\hline \multicolumn{4}{|l|}{ Salary } \\
\hline Less than $\$ 60,000$ & & & 25.2 \\
\hline$\$ 60,001$ to $\$ 80,000$ & & & 19.3 \\
\hline$\$ 80,001$ to $\$ 100,000$ & & & 17.6 \\
\hline$\$ 100,001$ to $\$ 120,000$ & & & 15.2 \\
\hline More than $\$ 120,000$ & & & 22.6 \\
\hline \multicolumn{4}{|l|}{ Country } \\
\hline Asia & & & 6.6 \\
\hline Europe \& Middle East & & & 7.7 \\
\hline North America & & & 82.4 \\
\hline South America & & & 3.2 \\
\hline
\end{tabular}

- whether or not they had stopped working at any point in their career and, if so, why;

- whether or not their career motives were different now from what they had been in the past and, if so, how; and

- whether or not they returned to work and, if so, what barriers they perceived to re-entry.

All of these questions were open-ended. Respondents' answers were not influenced by pre-specified categories, and they were free to include as many observations as they wished in their answers. Answers were coded into categories following an iterative process of code development and application by two coders (Boyatzis, 1998). There could be more than one answer to each of the questions, so percentages reported represent the proportion of women who mentioned that particular answer.

\section{Results}

Table II presents the results of the questions regarding opting out. Almost half of the women who responded to the survey ( 47 percent) had stopped working at some point in their careers. Of these 232 women, 47 percent said that they had stopped working to stay home with their children. Other reasons cited for stopping included having been laid off (16 percent), relocating (13 percent), being disillusioned with the corporate culture (10 percent), changing jobs ( 8 percent), continuing their education (7 percent), maternity leave or taking six months or less off to have a child (6 percent), starting their own business (4 percent), and being unsatisfied with their job (4 percent). Of the women who cited rearing their children as the reason they opted out of the workforce, 


\begin{tabular}{lc}
\hline Question & Percentage \\
\hline Have you stopped working at any point in your career? & \\
Yes & 46.7 \\
No & 39.0 \\
If so, why did you stop working? & \\
To rear children & 47.4 \\
Laid off & 16.4 \\
Relocated & 13.4 \\
Dislike corporate culture & 9.9 \\
Changed jobs & 8.2 \\
Further education & 6.5 \\
Maternity leave & 6.0 \\
Started own business & 3.5 \\
Unsatisfied with job & 3.5 \\
\hline
\end{tabular}

25 percent of them reported other reasons as well. So, just over a third (35 percent) of all of the women who stopped working did so only in order to rear their children.

Respondents' answers regarding changes in their career focus are reported in Table III. Of the women, 62 percent said "yes" their primary career motives had changed over time. Almost half of them (46 percent) said that work/life balance was more important to them when considering career options now than it had been in the past. A number of women reported being very disillusioned with corporate America and no longer wanting a corporate career (14 percent). Some mentioned having changed their career focus to a different industry (14 percent), while others cited their motivation to be self-employed (12 percent). Another change in career focus that women reported was that they now care more about a job that allows them help others or make a difference in the world (9 percent). Some final changes that were mentioned included being less ambitious ( 8 percent), the desire to travel less ( 6 percent), wanting a more enjoyable or rewarding job ( 6 percent), and being more focused on career advancement (2 percent).

\begin{tabular}{ll}
\hline Question & Percentage \\
\hline
\end{tabular}

Has your career focus changed over time?

Yes

No

How has your career focus changed?

Work/life balance is more important

Less interest in a corporate career

New career/industry focus

Desire to be self-employed

Desire to help others/make a difference

Less ambitious

Table III. Changes in career focus 
The KCM suggests that women's career focus, or primary career concern, changes throughout their career, moving from challenge in early career, to balance in mid-career, to authenticity in late career. In order to see if the women in our study followed a similar pattern, their responses regarding how their primary career motives had changed over time were recoded into the three Kaleidoscope Career categories. The desire for a more enjoyable or rewarding job and the desire to help others were coded as moves toward authenticity. Citing the importance of work/life balance, a desire to travel less, and having less ambition were coded as moves toward balance. Finally, moving into a new industry and increased interest in career advancement were coded as moves toward challenge. Having less interest in a corporate career was not included because this could represent a move toward either balance or authenticity. Likewise, the desire to be self-employed was not included because this could represent a move toward authenticity, balance, or challenge. Age was used to categorize women in their early career (35 years old and under), mid career (36-45 years old), and late career (46 years old and over).

In looking at the changes in career focus across the different career stages, women in early career mentioned the largest amount of change toward balance (65 percent), followed by challenge ( 27 percent), then authenticity ( 8 percent). The vast majority of women in mid career reported a change toward balance (75 percent), with the others being divided between a move toward challenge (13 percent) and a move toward authenticity (12 percent). Forty-four percent of the women in late career reported a change toward balance, followed by a move toward challenge (36 percent) and then authenticity (20 percent). For women at all career stages the biggest shift in career focus was toward balance. However, the percentage was highest for women in mid career, followed by women in early career. The shift toward challenge was highest in late career, followed by early career. Finally, the percentage of women who reported moving toward prioritizing authenticity continually increased from early to mid to late career. Percentages appear in Table IV.

Table V presents the results of the questions regarding re-entry into the workforce or opting in. Seventy percent of the women who reported having taken time off at some point in their career had returned to the workforce. Of those who had returned, the top reason for going back to work was to earn an income (45 percent). Many also returned because they enjoyed working (14 percent) or wanted intellectual stimulation (13 percent). Others mentioned that they re-entered the workforce to further their career development (13 percent), because an attractive job opportunity presented itself (10 percent), or because their children were older (6 percent). The average length of time that the women who returned had spent out of the workforce was 33.8 months, or close to three years. Almost half of the women (46 percent) were out of the workforce for less

Table IV.

Changes in career focus by career stage

\begin{tabular}{lccc}
\hline Career stage & Authenticity & $\begin{array}{c}\text { Career focus } \\
\text { Balance }\end{array}$ & Challenge \\
\hline Early career & 8 & 65 & 27 \\
Mid career & 12 & 75 & 13 \\
Late career & 20 & 44 & 36
\end{tabular}

Note: Numbers represent percentages 


\begin{tabular}{lc}
\hline Question & Percentage \\
\hline Have you returned to work? & 70.3 \\
Yes & 29.7 \\
No & \\
Why did you go back to work? & 45.4 \\
Income & 14.1 \\
Enjoy working & 12.9 \\
Intellectual stimulation & 12.9 \\
Career development & 9.8 \\
Job opportunity & 5.5 \\
Kids were older & \\
How long were you out of the workforce? & 45.9 \\
Less than 1 year & 26.8 \\
1-3 years & 27.3 \\
More than 3 years & \\
Why have you not returned to work? & 68.7 \\
Rearing children & 6.0 \\
No flexible/part time positions & 6.0 \\
Continuing education & 3.0 \\
Dislike corporate culture & 3.0 \\
No suitable jobs & Opting-in variables \\
\hline
\end{tabular}

than a year, while the rest of the women were evenly divided among those who stayed out from one to three years (27 percent) and those who stayed out longer than three years (27 percent).

A majority of the women who did not return to work stated that they chose not to rejoin the workforce because they were rearing their children (69 percent). Other reasons that were mentioned for not returning to work included the lack of availability of part-time or flexible jobs (6 percent), continuing their education (6 percent), disenchantment with the corporate world (3 percent), and no luck finding a suitable job (3 percent).

Of the women, 29 percent who returned to the workforce reported that they had a hard time finding a job. All of the women who had returned to work were asked what they perceived to be the major barriers for women trying to re-enter the workforce after a hiatus. Having skills that are out-of-date was perceived by 23 percent to be one of the major hurdles that women re-entering the workforce face. Both a lack of technological skills as well as current industry knowledge were mentioned here. Fifteen percent reported frustration regarding difficulties explaining a long period of unemployment. A number of women (13 percent) responded that age is a barrier for older women trying to re-enter the workforce.

Several (13 percent) felt that being able to successfully fulfill their family responsibilities after they returned to work was a big challenge. Achieving this balance between work and non-work may be difficult because another barrier that women noted was the lack of availability of flexible or part-time positions (11 percent). Some women felt there is a lack of respect for women who have taken time off from their 
careers (10 percent). Two final barriers to re-entering the workforce cited by several of the respondents were having lost their network of contacts ( 7 percent), which is so useful when searching for a new job, and the economy (7 percent). These results are presented in Table VI.

\section{Discussion}

According to the results of this study, many women are pursuing boundaryless careers. Almost half of the women surveyed had stopped working at some point in their career and the majority of them had since returned to the workforce. One important outcome of this study is that our findings do not support the claims of the recent media hype that women are opting out of the workforce in mass numbers to stay home with their children. First of all, while almost half of the women we surveyed had taken a hiatus from work, 70 percent of them had returned to the workforce and almost half of them were out of work for less than one year.

Furthermore, in line with the KCM predictions, the reasons women cited for leaving the workforce were complex. In fact, only 35 percent of the women who stopped working cited children as the sole factor in their decision to opt out. More often, numerous pull and push factors work in tandem to create the non-linear, interrupted patterns that characterize women's careers. Some examples of women mentioning more than one reason for leaving include: "I did not like the work environment of my company. I also felt like it was time for me to do something more meaningful", "I had my third child and we moved to England due to my husband's job", and "I was laid off from a dot.com in 2000, three weeks before the birth of my second child, so I took 6 months off before looking for a new position".

The difficulties of having a dual-career family led women to opt out of the workforce. Some respondents quit their jobs because they moved to a new geographic location when their spouses were relocated for their jobs. Others stopped working because their jobs required them to relocate and they were unwilling to do so because of their husband's jobs. These responses lend further support to the findings mentioned earlier that among individuals who have relocated for their job, the vast majority of accompanying spouses are women (Eby, 2001).

Table VI.

Perceived barriers to the boundaryless career
Question

Percentage

When you were ready to return to work, was finding a job difficult?

Yes

No

What do you consider the major barriers to re-entering the workforce?

Skills/experience not up-to-date

Long period of unemployment

14.7

Family responsibilities

13.4

Age

12.9

No flexible/part time positions

11.2

No respect for women who take time off $\quad 9.5$

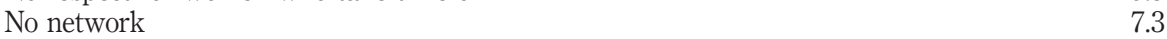

$\begin{array}{ll}\text { Economy } & 7.3\end{array}$ 
Of the respondents, 16 percent reported being laid off as their reason for leaving the workforce. This evidence lends credence to Boushey's (2005) attempt to "debunk the myth" that women are opting out to stay at home with their children. She argues that the recession of the early 2000s led to job losses for all women, making it appear that they were opting out. She presents economic data showing that children have a very small effect on women's workforce participation. So again, the situation is more complex than women simply walking away from their careers to rear their children.

Our results also provide evidence for the existence of the three career parameters identified in the KCM as influencing the decisions that create career patterns across the lifespan. Sixty-two percent of the women reported that their career focus had changed over time. When they were asked in what way the focus was different, each of the answers coded fit into at least one of the categories of authenticity, balance, or challenge.

Furthermore, some of the changes in career focus reported by women at different career stages followed the Beta Kaleidoscope Career Pattern predicted for women by the KCM. In particular, women at mid career showed the highest percentage of moves toward an emphasis on balance. Some of their comments were: "The jobs in which I have been successful have always demanded too much time and stress to offer much in the way of work/life balance. I honestly don't see how one can simultaneously give family and career both the $100 \%$ they deserve", and "No one stopped to help us figure out how to have the top career we were trained for and be the mother we emulate from home. It can't be done". Another commented that she had already proven herself at work so she could now leave it behind to dedicate herself to her family.

There were also a lot of women in early career who had shifted toward a focus on balance. This is not surprising given that early career women were categorized as those younger than 36 years old, and it is likely that many of them are already experiencing problems integrating their work and non-work lives. However, again in line with the KCM, a higher percentage of women in early career were focused on challenge than of those in mid career. More of them mentioned being interested in career advancement and moving up the ladder.

These results provide preliminary evidence for the KCM proposition that women often begin their careers with an emphasis on challenge and later move toward a greater concern for balance. The vast majority of the women surveyed had early careers in international business, many in large organizations. They traveled the world, worked hard, and earned high salaries. But many later realized that these types of jobs were incompatible with rearing a family. One woman observed, "After 8 years and 2 countries of managing a foreign office of a US subsidiary with an operational budget of more than US $\$ 30$ million a year under my management, I question the importance I have placed on my work at the expense of my family". Another said, "I started out with a lot of ambition and wanted to get to the top, but as I've grown, I think a balance is more important". And one woman stated simply, "I no longer want to climb to the top. I'd rather have life balance".

Our results also showed, again as the KCM suggests, that the percentage of women who had moved toward a focus on authenticity grew progressively from early to mid to late career. There were numerous examples of women moving toward authenticity. One woman left her job as Account Director to teach remedial math, saying it was time for her to give back. Another said, "I want to build something. When I was in my 20 s it was about the money, now it is about really having an impact in an area that I care 
about". A third insightful comment was: "As I got older, it became more difficult to follow orders, rules or the status quo within the corporate environment. Now, I want to pursue my own agenda, my own ideas, my own vision”.

Respondents expressed the desire to work for non-profit organizations. They mentioned wanting to help others, contribute to positive social change, make a difference in the world, and work for a cause about which they were passionate. An interesting story is the woman who had a successful but unfulfilling career for six years that she quit in order to work in the humanitarian non-profit sector in African war zones. She is currently pursuing a $\mathrm{PhD}$ in cultural anthropology with a focus on violence and religion. All of these examples are in line with the $\mathrm{KCM}$ view that in their late career women seek jobs that allow them to be true to themselves, often searching for meaning and spirituality in their lives. As one woman put it, "It is more important at this stage of my life for the work to be very rewarding".

Moves toward authenticity were also seen in women who left their jobs because they were unhappy working in the masculine culture that dominated their companies. One referred to her organization as a "wretched, chauvinistic, and anti-women environment", while another described hers as having a "male dominated mentality". The following comments support the idea that women may leave organizations because of ethical conflicts: "Greedy CEOs and managers have made corporate America distasteful to me. Ethics and dependability matter less than schmoozing", and "I would rather live with myself than rationalize away my character in order to obtain more power". The drive for authenticity leads women to leave organizational cultures that clash with their values in order to be true to themselves.

Finally, the results of our study show that there are boundaries or barriers to the boundaryless career. Twenty-nine percent of the women who returned to work reported that it was difficult to re-enter the workforce. When asked about perceived barriers to re-entry, the barrier mentioned the most was having out-of-date skills due to the time spent out of the workforce. One respondent lamented that the difficulty of "keeping current on technology and work trends" while out of work was a major barrier to re-entry. A woman in the technology field said she would be "considered not up-to-date on the latest software developments and their practical applications".

Other researchers have suggested that learning might be negatively impacted when individuals pursue careers outside of organizations. Mallon and Walton (2005) found that individuals who engaged in boundaryless careers by leaving organizations to work as self-employed individuals on projects often neglected their training and development needs. The authors concluded that people still rely on organizations for support in their learning endeavors, arguing that careers are not as self-directed as the career literature has implied. Baruch (2006) has echoed this idea that, although careers are becoming more individualistic, organizations still play an important role in the support and development of individuals. In this case, individuals who pursue boundaryless careers may be at a disadvantage when it comes to knowing-how. They have neither the support nor the direction that organizations can offer as far as learning and growth. Individuals who leave organizations not only lose access to organizational training, they also often have trouble identifying the type of learning they should be doing (Mallon and Walton, 2005).

Keeping skills up-to-date is an important challenge for women who stop working because the knowing-how competency is one of the key elements of the intelligent 
career. A second key competency, knowing-whom, also appears to be a boundary faced by women who take a hiatus from their careers. Specifically, women mentioned the lack of a network of contacts as being a barrier to re-entering the workforce. One woman said, "Being at home full time with young children, it has been difficult maintaining contacts in the field, even with previous employers/colleagues". So two of the barriers mentioned by respondents are the fact that knowing-how and knowing-why competencies are negatively impacted by taking time off, thus hampering the potential success of a boundaryless career.

Most of the other barriers to re-entry cited by respondents are related to the previously discussed push and pull factors that lead women to quit work in the first place. For example, two perceived barriers were difficulty explaining long periods of unemployment and a lack of respect for women who have taken time off from their careers. One woman lamented, "Companies interviewing do not understand when a worker leaves the company because of personal issues. They think [...] there is something wrong with you". Women expressed frustration that some employers believe women who have children are less committed to their job. One said, "In interviews I get the feeling that having young children is viewed negatively. I was questioned about my ability to commit and how I would be able to work long hours when necessary". According to another respondent, "If you are in child-bearing years there is always a question about your commitment to the organization long term. I was laid off less than two weeks after I told my boss that I was pregnant”.

Both of these barriers stem from the masculinity of organizational cultures. Men tend to be work-centric, compartmentalizing work and non-work and subordinating all non-work activities and commitments to their career advancement (Maier, 1999). Because of this, in masculine organizational cultures, performance and commitment are judged by the time spent working. So individuals who take time off from work are viewed as less committed, thus presenting another boundary for women's careers. They are discriminated against because they are relational and prefer to integrate work and family, which goes against the dominant masculine corporate values (Mainiero and Sullivan, 2006). One woman commented that "The political factors overshadow the value and weight of good work and professionalism".

Difficulty maintaining a balance between work and family responsibilities and the lack of availability of flexible or part-time positions were also cited as barriers to re-entry. These combine the pull factor of care-taking responsibilities with the push factor of organizations not being willing to change their structures to accommodate employees' desires to integrate work and life, likely stemming again from the masculine culture. Many women mentioned that they would have preferred to continue working, but it was too hard to balance their families' needs with a full-time job. One respondent said "I would be perfectly happy to work from 8.30 to 2.30 - I'd be able to dedicate time to my family and spend quality time at work". Yet several lamented that there are very few meaningful opportunities for part-time careers. One woman observed that reduced work schedules often mean less pay for the same work or less interesting work, while another said that part-time becomes full-time very quickly.

So, while it has been suggested that women may be better suited for pursuing boundaryless careers, our findings show that boundaries do exist, particularly for women. The women in our study listed a number of barriers that make it difficult to move across organizations, especially if one takes time off between jobs. These 
boundaries include the negative impact that taking time off has on knowing-how and knowing-why competencies. Moreover, the same push and pull factors that influence women's decisions to leave the workforce are also hindering their ability to return. Organizational structures and cultures continue to work against women who, rather than compartmentalizing their worlds, choose to integrate work and family. Taking time off is viewed as a lack of commitment to one's career, and work structures have not changed in order to permit women to successfully combine their different life domains.

\section{Practical implications}

The complex interplay of push and pull factors affecting women's career decisions will continue to drive many of them to leave the workforce at some point in their career. Identifying the barriers that women face in pursuing boundaryless careers is the first step toward learning how to minimize them. Some of the barriers can be reduced by women themselves. They should start planning for re-entry the day they step out. There are a number of things that women can do during their hiatus to keep their skills up to date and have something to put on their resumes. They should keep abreast of industry and technological changes by working on projects, remaining active in professional associations, volunteering, attending conferences, or taking classes. Women should be especially careful not to neglect their learning and growth, as Mallon and Walton (2005) found often occurs when individuals become disconnected from organizations.

Participation in these activities will also keep women connected to contacts who may help them get a job when they are ready. For example, one woman observed that going back was "only not difficult because I did freelance work through contacts that I had made". Keeping active lets women pursue intelligent careers by helping them minimize the negative impact taking time off can have on knowing-how and knowing-why competencies.

Some women prefer to start their own business rather than return to corporate America. Four percent of the respondents in our study had already started their own business and 12 percent hoped to do so one day. Women expressed an interest in self-employment in order to satisfy their need for balance. This can be seen in the following comments: "I would like to start my own company and therefore have some degree of control over my destiny and the amount of time I spend with my family", "I am interested in starting up my own company so I can dictate my schedule", and "I feel that, especially for women with children, flexibility in the workforce is a necessity that is usually not available. At this point, with an 11 and 7 year old, I am seriously considering opening my own insurance brokerage firm”.

In addition to looking for balance, women also mention preferring self-employment to working in the masculine organizational cultures that they experienced in the corporate world. In her book Careerpreneurs, Dorothy Moore (2000) reports that one out of every five women who has started a business was pushed out of her former job by the "good-old-boy system". She points out that the percentage of women leaving organizations because they had an entrepreneurial idea has dropped from 50 percent to 35 percent over the last 20 years, while the number having left due to lack of opportunity, downsizing, or lack of fulfillment has risen from 25 percent to 46 percent. A respondent in our study said, "After making it to senior levels in those big 
corporations I never want to work there again. I want to remain self-employed the rest of my life. It has nothing to do with flexibility [...] it has to do with not playing politics all day". Another woman commented: "I am not interested in playing the games or abiding by the rules in most large corporations. I would like to start my own company".

Entrepreneurship is also an attractive option for women who may have to relocate in order to follow their spouse, for single mothers, and for other women who cannot afford to stop working. Fortunately, the human and social capital or embedded career capital that professional women have accrued in the past may help them to be successful in entrepreneurial endeavors (Terjesen, 2005). Moore (2000) found that individuals were more successful in starting their own business if they had previous experience working in corporations. The most successful entrepreneurs started businesses in a similar field and were able to transfer information from their prior organization to their new venture.

Organizations and universities can play a key role in minimizing the difficulties that re-entry women face (McGrath et al., 2005). Organizations are starting to recognize the value of not losing talented women who feel the need to step out temporarily. This phenomenon is being referred to as the new brain drain (Hewlett and Luce, 2005) and is an especially disturbing trend for organizations given the growing percentage of women earning professional degrees and the looming labor shortage that will hit as the baby boomers start retiring. It is in the best interest of organizations to try to prevent women from feeling the need to leave by offering more flexible schedules, reduced load options, job sharing, and part-time positions. Attitudes must also change so that there is no stigmatization attached to using alternative work arrangements, nor are there career penalties. Life-track thinking must become a part of organizational values and norms (Mainiero and Sullivan, 2006).

In cases where women still decide to leave, organizations can make efforts to keep them connected, offer on-going training, and provide an on-ramp when they are ready to come back. Mainiero and Sullivan (2006) offer many suggestions regarding steps that organizations can take to retain women, such as redesigning work to make it more flexible, creating alternative career paths, making top management responsible for advancement rates of women, rewarding performance rather than face time, and fostering cultures that are truly family-friendly. Unfortunately, while some enlightened organizations have made moves in this direction, they are the exceptions. As Baruch (2006) has pointed out, the traditional career focus in most organizations is far from dead.

Universities can do a lot to help women manage their boundaryless careers. Alumni offices could offer career services to women returning to the workforce, such as giving refresher courses, offering seminars on job search skills, and providing opportunities for networking. An especially useful course for women would be one on entrepreneurship. We have already mentioned that several women in our study expressed an interest in starting their own business. According to the Center for Women's Business Research (2006), 48 percent of all privately-held US companies are 50 percent or more women-owned and the estimated growth rate for these firms is nearly twice that of all firms. Given that self-employment is such an attractive option for women, universities should offer classes in entrepreneurship as part of their basic curriculum. They should also seize the opportunity to offer continuing education classes focused on the ins and outs of starting one's own business for women who later decide to become self-employed. 


\section{Conclusions}

This paper makes a contribution to two distinct areas of career theory. It presents one of the first empirical studies of the KCM. Results dispute the media hype that women are opting out of their careers to stay at home with their children; in most cases the situation is more complex. It also provides evidence for the three parameters that the KCM suggests influence women's career decisions. The second contribution is in the area of boundaryless careers. Our findings demonstrate that women do face boundaries when pursuing careers across organizations.

We acknowledge the limitations of this research in terms of limited generalizability and possible response bias. Although our sample included a large number of diverse women, they were all professionals with a graduate degree in international business. Thus, our findings may have limited generalizability. Many of the respondents are likely married to professional spouses as well, in which case they could afford not to work. This is obviously not the case for most women who do not have the option of quitting their jobs. Also, as mentioned previously, the response rate is lower than desired. Although comparisons of respondents with non-respondents revealed no differences, the possibility of response bias always exists. Despite these limitations, we believe this study provides valuable data that helps us to better understand the complexities of women's career paths.

Given that ours was one of the first empirical studies of the KCM, further research is needed to corroborate our findings as well as to test the model with different populations. Mainiero and Sullivan (2005) proposed the KCM for both men and women at various income levels, but our study only tested it for professional women. More research is also needed to identify the best strategies for minimizing the boundaries faced by women pursuing boundaryless careers. Future studies could identify women who did not have trouble returning to work after a hiatus in order to determine what they did to reduce the difficulties of re-entry. It would also be interesting to empirically study the different strategies that have been proposed for minimizing boundaries to investigate which ones have a greater impact on the successful return to work.

\section{References}

Altman, Y., Simpson, R., Baruch, Y. and Burke, R. (2005), "Reframing the 'glass ceiling' debate", in Burke, R.J. and Mattis, M.C. (Eds), Supporting Women's Career Advancement: Challenges and Opportunities, Edward Elgar, Cheltenham, pp. 58-81.

Arthur, M.B., Claman, P.H. and DeFillippi, R.J. (1995), "Intelligent enterprise, intelligent career", Academy of Management Executive, Vol. 9 No. 4, pp. 7-22.

Arthur, M.B. and Rousseau, D.M. (1996), "Introduction: the boundaryless career as a new employment principle", in Arthur, M.B. and Rousseau, D.M. (Eds), The Boundaryless Career, Oxford University Press, New York, NY, pp. 3-20.

Baruch, Y. (1999), "Response rate in academic studies - a comparative analysis", Human Relations, Vol. 52 No. 4, pp. 421-38.

Baruch, Y. (2004), "Transforming careers: from linear to multidirectional career paths", Career Development International, Vol. 9 No. 1, pp. 58-73.

Baruch, Y. (2006), "Career development in organizations and beyond: balancing traditional and contemporary viewpoints", Human Resource Management Review, Vol. 16, pp. 125-38.

Belkin, L. (2003), “The opt-out revolution”, New York Times Magazine, October 26, p. 42. 
Boyatzis, R.E. (1998), Transforming Qualitative Information, Sage Publications, Thousand Oaks, CA.

Boushey, H. (2005), “Are women opting out? Debunking the myth”, Center for Economic and Policy Research, Washington DC, available at: www.cepr.net/publications/opt_out_2005_ 11.pdf (accessed October 9, 2006).

Burke, R.J. and Mattis, M.C. (2005), Supporting Women's Career Advancement: Challenges and Opportunities, Edward Elgar, Cheltenham.

Burke, R.J. and Vinnicombe, S. (2005), “Advancing women's careers”, Career Development International, Vol. 10 No. 3, pp. 165-7.

Burke, R.J. and Vinnicombe, S. (2006), "Supporting women's career advancement”, Women in Management Review, Vol. 21 No. 1, pp. 7-9.

Catalyst (2005), "Census of women corporate officers and top earners of the Fortune 500", available at: www.catalystwomen.org/ (accessed September 14, 2006).

Center for Women's Business Research (2006), "Women-owned businesses continue to outpace growth rates for all other firms", available at: www.womensbusinessresearch.org/press/ details.php?id = 135 (accessed September 3, 2006).

Cross, C. and Linehan, M. (2006), "Barriers to advancing female careers in the high-tech sector: empirical evidence from Ireland”, Women in Management Review, Vol. 21 No. 1, pp. 28-39.

DeFillippi, R.J. and Arthur, M.B. (1994), "The boundaryless career: a competency-based perspective”, Journal of Organizational Behavior, Vol. 15 No. 4, pp. 307-24.

Eby, L.T. (2001), "The boundaryless career experiences of mobile spouses in dual-earner marriages", Group \& Organization Management, Vol. 26 No. 3, pp. 343-68.

Equal Employment Opportunity Commission (2006), "Sexual harassment", available at: www. eeoc.gov/types/sexual_harassment.html (accessed September 19, 2006).

Fondas, N. (1996), "Feminization at work: career implications", in Arthur, M.B. and Rousseau, D.M. (Eds), The Boundaryless Career, Oxford University Press, New York, NY, pp. 282-93.

Gilligan, C. (1982), In a Different Voice: Psychological Theory and Women's Development, Harvard University Press, Cambridge, MA.

Gross, J. (2005), "The daughter track: caring for the parents", International Herald Tribune, November 24.

Hall, D.T. (1996), The Career is Dead - Long Live the Career, Jossey-Bass, San Francisco, CA.

Hewlett, S.A. and Luce, C.B. (2005), "Off-ramps and on-ramps: keeping talented women on the road to success", Harvard Business Review, March, pp. 43-54.

King, Z., Burke, S. and Pemberton, J. (2005), "The 'bounded' career: an empirical study of human capital, career mobility and employment outcomes in a mediated labour market”, Human Relations, Vol. 58 No. 8, pp. 981-1007.

McGrath, M., Driscoll, M. and Gross, M. (2005), Back in the Game, Wharton Center for Leadership and Change, Pennsylvania, PA.

Mallon, M. and Walton, S. (2005), "Career and learning: the ins and the outs of it", Personnel Review, Vol. 34 No. 4, pp. 468-87.

Maier, M. (1999), "On the gendered substructure of organization: dimensions and dilemmas of corporate masculinity", in Powell, G.N. (Ed.), Handbook of Gender and Work, Sage Publications, Thousand Oaks, CA, pp. 69-93.

Mainiero, L.A. and Sullivan, S.E. (2005), "Kaleidoscope careers: an alternative explanation for the opt-out revolution”, Academy of Management Executive, Vol. 19 No. 1, pp. 106-23. 
Mainiero, L.A. and Sullivan, S.E. (2006), The Opt-Out Revolt: Why People are Leaving Companies to Create Kaleidoscope Careers, Davies-Black Publishing, Mountain View, CA.

Marshall, J. (1995), Women Managers Moving On: Exploring Career and Life Choices, Routledge, London.

Moore, D.P. (2000), Careerpreneurs: Lessons from Leading Women Entrepreneurs on Building a Career Without Boundaries, Davies-Black Publishing, Palo Alto, CA.

Peiperl, M. and Baruch, Y. (1997), "Back to square zero: the post-corporate career", Organizational Dynamics, Vol. Spring, pp. 7-22.

Powell, G.N. (1999), "Reflections on the glass ceiling", in Powell, G.N. (Ed.), Handbook of Gender and Work, Sage Publications, Thousand Oaks, CA, pp. 325-45.

Powell, G.N. and Mainiero, L.A. (1992), "Cross-currents in the river of time: conceptualizing the complexities of women's careers”, Journal of Management, Vol. 18 No. 2, pp. 215-37.

Powell, G.N., Butterfield, D.A. and Parent, J.D. (2002), "Gender and managerial stereotypes: have the times changed?”, Journal of Management, Vol. 28 No. 2, pp. 177-93.

Reitman, F. and Schneer, J.A. (2005), "The long-term negative impacts of managerial career interruptions”, Group \& Organization Management, Vol. 30 No. 3, pp. 243-62.

Schwartz, F.N. (1989), "Management women and the new facts of life", Harvard Business Review, Vol. 67 No. 1, pp. 65-77.

Singh, V., Vinnicombe, S. and James, K. (2006), “Constructing a professional identity: how young female managers use role models”, Women in Management Review, Vol. 21 No. 1, pp. 67-81.

Story, L. (2005), "Many women at elite colleges set career path to motherhood", New York Times, September 20, p. A1.

Sullivan, S.E. (1999), "The changing nature of careers: a review and research agenda”, Journal of Management, Vol. 25 No. 3, pp. 457-84.

Terjesen, S. (2005), "Senior women managers' transition to entrepreneurship: leveraging embedded career capital”, Career Development International, Vol. 10 No. 3, pp. 246-59.

US Bureau of Labor Statistics (2005a), "Women in the labor force: a databook", available at: www.bls.gov/cps/home.htm (accessed September 28, 2006).

US Bureau of Labor Statistics (2005b), "Data by occupation and gender (computed from Table 39)", available at: www.bls.gov/bls/blswage (accessed September 18, 2006).

Valcour, P.M. and Tolbert, P.S. (2003), "Gender, family, and career in the era of boundarylessness: determinants and effects of intra- and inter-organizational mobility", International Journal of Human Resource Management, Vol. 14 No. 5, pp. 768-87.

van Vianen, A.E.M. and Fischer, A.H. (2002), "Illuminating the glass ceiling: the role of organizational culture preferences", Journal of Occupational and Organizational Psychology, Vol. 75, pp. 315-38.

Vanderkam, L. (2005), “A new mommy track”, USA Today, December 6.

Vinnicombe, S. and Bank, J. (2003), Women with Attitude: Lessons for Career Management, Routledge, London.

Vinnicombe, S. and Singh, V. (2002), "Sex role stereotyping and requisites of successful top managers", Women in Management Review, Vol. 17 Nos 3/4, pp. 120-30.

Wallis, C. (2004), "The case for staying home”, Time, March 22, pp. 51-9. 


\title{
Further reading
}

de Janasz, S.C., Sullivan, S.E. and Whiting, V. (2003), "Mentor networks and career success: lessons for turbulent times", Academy of Management Executive, Vol. 17 No. 4, pp. 78-91.

\begin{abstract}
About the author
Elizabeth F. Cabrera is a Professor in the School of Global Management and Leadership at Arizona State University. Prior to joining ASU she was a Professor at Universidad Carlos III in Madrid, Spain. She received her $\mathrm{PhD}$ in Industrial/Organizational Psychology from Georgia Tech. Her current research interests include women's careers and work/life integration. She has published articles in journals such as Human Resource Planning, International Journal of Human Resource Management, International Journal of Selection and Assessment, Journal of World Business, Management Research, and Organization Studies. She serves on several editorial boards and is the editor of Management Research. Elizabeth Cabrera can be contracted at: beth.cabrera@asu.edu
\end{abstract}

